\title{
Clothing Sustainability and Upcycling in Ghana
}

\author{
Alberta St. John James and Anthony Kent* \\ Nottingham Trent University
}

${ }^{*}$ Corresponding author

Anthony Kent

School of Art and Design

Nottingham Trent University

50 Shakespeare St.

Nottingham NG1 4FQ

\section{Autobiographies}

Tony Kent is Professor of Fashion Marketing in the School of Art and Design at Nottingham Trent University. His research interests include fashion retail, sustainability and personalisation of fashion. He is an Executive member and Chair of the Research Committee of IFFTI, Fellow of the Royal Society of Arts, and Fellow of the Higher Education Institute.

Alberta St. John-James is a London based fashion designer and educator. She is a founding member of Africa Fashion Incubator (AFI). AFI Ghana is an NGO established in Ghana to promote sustainable fashion design practise, enterprise and skills development. She is currently researching upcycling waste clothing at Nottingham Trent University. 


\title{
Clothing Sustainability and Upcycling in Ghana
}

\begin{abstract}
The aim of this paper is to assess opportunities for the upcycling of waste clothing through design workshops held in Accra, Ghana. An upcycling approach to clothing longevity examines how garments can be re-designed and resold in a new form. Significant amounts of surplus and second-hand clothing from the developed world and large producer nations, for example China, are distributed to Africa and sold in local markets at affordable prices. The research was conducted into upcycling waste clothing from the market by five groups of fashion design students at Accra Technical University (ATU). A participatory research design was applied to the project and the initial briefing to design groups confirmed the concept of upcycling and the design parameters. Each group defined a design theme, made a selection of clothes and accessories in the Accra market and returned to the university to conceptualise and re-create clothes and accessories. The project culminated in presentations of finished garments modelled by the students. It addressed the disposal stage of the circular economy model of clothing sustainability by providing new knowledge of how waste clothing, readily available in a developing country's market can be sourced and creatively re-designed into new garments and accessories.
\end{abstract}

\section{Keywords}

Design, fashion, upcycling, Africa, re-use

"No potential conflict of interest was reported by the authors." 


\section{Introduction}

The sustainability of the fashion industry has become increasingly important amidst growing concerns about its use of resources and impact on the environment. In tackling problems of efficiency, waste reduction and wider economic benefits, the industry is responding to a growing momentum towards a circular economy, a model of production and consumption that provides an alternative to the traditional linear economy where products are manufactured, used and disposed of (Claxton and Kent, 2017; Prieto-Sandoval, Jaca and Ormazabal, 2018).

A significant element of the circular model in fashion clothing is to increase its longevity, and thereby reduce consumption, by designing for durability or emotional attachment (Gwilt 2014). Typically when the consumer is disposing of a garment, at an end of life phase, the focus is on the re-use of its fibres and how these can be used in new garment construction. However a recognised alternative approach is to examine how used clothing can be re-designed and upcycled for resale in some new form. Surplus clothing from the fast fashion industry including end of line products and quality rejects, can be re-processed in this way. Upcycling, by contrast to recycling, adds value to materials as they are created into new forms. It has the potential to contribute to economic development, by employing people to make value added clothes and accessories, to sell to developed markets.

In the UK alone, it is estimated that around 1.8 million tonnes of waste are generated annually from garments, accounting for around 5\% of total UK household waste (Cooper et al., 2013). In the linear model of fashion production and consumption, their usable life ends in a disposal phase, resulting in landfill, recycling for their textile content or distribution to developing 
countries, with around $75 \%$ of collected textiles exported for re-use overseas (Bartlett, McGill and Willis, 2013). However, the disposal of waste clothing in Africa has led to a number of economic opportunities and problems. While there is evidence in some countries that it has a positive economic effect (Haggblade,1990), in other cases it diminishes local textile and clothing production and creates a precarious business structure (Brooks 2012). Ghana is one African country where this has happened; a very well-developed trade in waste fashion products from overseas has resulted in a wide range of clothing, shoes and accessories being bought and worn by local people, and a decline in the local textile industry. While the markets provide employment and some repair and renovation of used clothing, there is less evidence of higher value-adding activities. The aim of this paper is to assess the opportunities to add value to waste clothing by upcycling it through the conceptualisation and re-design of materials bought in the clothing market in Accra.

\section{Literature Review}

The indicators of sustainable fashion encompass local and ethical production systems, fair trade principles, eco-friendly or recycled materials and longer product lifecycle (Joergens, 2006; Fletcher, 2008). In the fashion industry a 'cradle to cradle' or circular model is recognised as an ideal model for sustainability (McDonough and Braungart, 2009; Fletcher and Grose, 2012). The model aims to keep resources in active use for as long as possible, to extract the highest possible value from them while in use, then to recover and recycle them at the end of life (WRAP 2015). Waste should be eliminated through the stages of the entire product lifecycle from design to disposal (Gwilt 2014; McDonough and Braungart, 2009). 
The disposal stage of the fashion product lifecycle sees many garments donated to charity organisations for re-selling in local or overseas second-hand markets (Balch, 2013; Cooper et al., 2013; Claxton and Kent, 2017). Retailers such as H\&M and Marks \& Spencer provide clothing take-back services where customers can deposit unwanted items in clothing bins for re-cycling. Another sustainable approach is for garments to be designed for disassembly, where products are developed that can be taken apart to replace worn or damaged components (Gwilt and Rissanen, 2010).

Significant amounts of surplus and second-hand clothing from the developed world but also producer nations, specifically China, are distributed to Africa to be sold in local markets at affordable prices. Previous research has demonstrated how the distribution of waste clothing through markets increases employment and expands rural economies (Haggblade, 1990; Baden and Barber, 2005) and the informal sector (Langevang and Gough, 2012). In some countries these trends in second-hand clothing are well established, and by 1980 accounted for 30-50\% of all garments sold in Ghana, Benin, Togo and Zaire (Haggblade, 1990). Consequently, Ghana has a very well-developed trade in surplus fashion merchandise, where a wide range of clothing, shoes and accessories are bought and worn by local people.

Many consumers purchase clothing items displayed on the ground in markets across the country (Abimbola 2012). The largest of these is the Kantamanto market, which occupies two acres in the centre of the capital Accra and has operated for over sixty-five years selling second hand commodities, especially used clothing. While pressure on space presents a detrimental health and safety risk, Kanatamanto is, nevertheless a resilient market, recovering from a devastating fire in 2013 to retain its place as the most powerful trading space in Accra. The 
market is known by several names such as "Bend down boutique", "Cants" and "Broni waawu" (dead white persons clothing) amongst others and began by serving commuters travelling to and from the capital. It expanded to attract not only local traders and consumers but also wholesalers and retailers who travel from all sixteen regions of Ghana to buy bails of clothing items to sell in other urban and rural areas across the country. This level of trading creates a significant level of sustainable employment; it is estimated that approximately thirty-nine thousand people of whom over thirty-five percent are women, are employed there (OtengAbabio et al. 2015). Combined, the traders, agents and street sellers' who are mostly uneducated, generate sales from all second-hand goods, including clothing, of around \$2550m. per week (Oteng-Ababio et al. 2015).

However, Brooks's (2012) study of markets in Maputo found that, as the supply of fashionable clothing is determined by the developed world suppliers, traders have little influence over the system and experience unpredictable livelihoods. Moreover, it has also had a reciprocal effect in facilitating the decline of established fashion and clothing businesses (Baden and Barber, 2005; Frazer, 2008; Brooks 2015). In Ghana, this substitution has resulted in the decline of locally designed and made clothing produced for the mass market (Adikorley, 2013).

One solution to the regeneration of the local clothing industry is to examine the possibilities for upcycling clothing from the markets. The upcycling process is defined as maintaining or upgrading materials' value and quality beyond their initial life to a second life and beyond (Braungart, McDonough and Bollinger 2007; Ellen MacArthur Foundation 2015). In fashion and textiles, the focus of upcycling can be on refashioning (Fraser 2011) resurfacing (Goldsworthy 2009) and re-cutting but essentially "recovering intrinsic value and closing the 
loop of the manufacturing system" (Han et al. 2017, p.71). More specifically the small-scale creation of jewellery, bags, clothes and other fashion items by upcycling waste and recyclable material has been described as 'trashion' (Bramston and Maycroft, 2013). Upcycling provides an opportunity to re-create original pieces even from damaged clothing by using the durable parts of the garment (Oxfam n.d.). These value-adding processes are evident in practices such as mending and sorting of outfits by workers in the local market economy in Zambia (Hansen 2000). Such practices are also found in the Accra market, where torn and damaged denim garments are repaired by sewing machinists and hand-dyed where the workers decide the colour should be renewed.

Other upcycling initiatives with waste clothing are designer-led but these tend to be small scale. For example, in Malawi, designer Mia Nisbet demonstrated the use of recycled fabrics and traditional Malawian textiles in a collection that combined the richness of African textiles with Western design (Shaw, 2013). This was found to be a complex process because of its involvement with deconstruction, re-design and then the reconstruction of second-hand clothing (Shaw, 2013). In the case of Ghana, local skills such as printing, dying and weaving can be incorporated into the designing process to create narratives of heritage and identity in each designed piece. Upcycling design can allow each clothing item to become unique, either in a limited edition or in mass production (Gardetti and Torres 2013, pp. 149-162). However, while a designer approach to upcycling and an artisanal one by sewers and repairers is documented, less is known about the ways in which design for upcycling can be learned and more widely applied in the community. 
The contribution of upcycling design to the principles of sustainable design is that, as a design strategy or methodology, it considers the impact of the product on the environment at a particular stage of the product lifecycle. In this study, it focuses on the impact on the competitiveness and decline of the Ghanaian textile industry and the environment by finding alternative uses for waste clothing. Further, if sustainable design requires systemic thinking about the environmental impact of waste clothing among, producers, retailers, suppliers and consumers throughout the lifecycle of goods, then it becomes more complex in terms of its social impact and embeddedness in society (Liedtke, Buhl and Ameli, 2013; Manzini, 2015). One means of achieving this embeddedness is to enable young fashion designers to be involved in the re-design of waste garments into new marketable products to extend their lifecycle.

The need to educate fashion designers in sustainability and specifically in upcycling requires more detailed attention (DeLong et al. 2017; Lee and DeLong, 2018). Changes in fashion design require new designers to develop skills in teamwork, communication, problem solving and inter-disciplinary knowledge (Bye, 2010). Further, while sustainable materials, manufacturing processes and resource efficiency are valuable dimensions of the circular economy model, sustainability experts propose that innovation is needed in design practice, technology and business modelling (Ellen MacArthur Foundation, 2015). In Ghana, the concepts and practices of sustainability are not well known; however, the markets are so well established that young people, as consumers, have a very good first-hand knowledge of local market conditions, product quality and availability. These provide the conditions for fashion students to meet the design challenges of upcycling in the developing world. 
This project addresses the consumer use and disposal stages of the circular economy in order to reduce waste by gaining more value from clothing that has been used or is surplus, unused stock residing in the fashion system. It focuses on upcycling for a second life rather than the potential beyond this stage, for example design for multiple future garment and materials uses. The research question that arises from the review of the sustainable fashion literature is how can waste clothing be re-designed to create value-adding new items, through facilitated workshops.

\section{Methodology}

The research methodology recognises design as necessarily capturing the relationship between the creative process and realised solution and which demonstrates "the intentional solution of a problem, by the creation of plans for a new sort of thing..." (Parsons, 2016, p.11). It builds on the principles of design as 'know how', and that design principles are best found in the utility and functionality that bound the design problem.

Practice is fundamental to the action research strategy used in this project that integrates experience, action and reflection (Bye, 2010; Reason, 1994). It fosters collaboration among its participants to advance both knowledge and practical problem solving (McGrath and O'Toole, 2012). Practical or iterative Action Research aspires to change, but also informs the practical decision making of practitioners to identify problems, determine solutions and evaluate outcomes (Kemmis, 2006, cited in McGrath and O'Toole, 2012, p.95). This approach leads to a better understanding of the underlying problems and their causes with the researcher and the practitioners jointly identifying possible interventions. Further it allows for a more flexible approach in design and delivery that accommodates co-design practices (Manzini, 2015; 
Sanders and Stappers, 2012) and creates value (Piller et al., 2005: online). In particular, education for sustainability can include an active approach to learning and student-centredness (Aditomo et al., 2013). The locus of control is with the learner, with the teacher as facilitator of learning (Hurney et al., 2017).

In working with students in Accra, it was recognised that learning experiences should be tailored to circumstances in different places and contexts and should empower students to address environmental issues in different situations (Pretorius et al., 2016). This has been identified as a definite need in the African context (Manteaw, 2012) and develops Hill et al.'s (2015) findings that demonstrate the opportunities for upcycling in Accra, using students to redesign clothing sourced in the local market. The research was undertaken with five groups of third year fashion design students at Accra Technical University. It began with each group envisioning a design theme and creating a storyboard. The first of five themes was gathering and hunting, interpreted through garments that represented an ancient tradition and their restoration. The second theme was the beauty of nature, taking its inspiration from the patterns of plants, relating upcycled designs to these patterns and specifically designs to reduce deforestation. The third theme was 'Everyone needs someone', for garments to communicate a message of reconciliation. 'Architecture and monarchy' formed the fourth theme; for example through the influence of a king or sovereign on architectural design. The final theme was the 'degraded economy' which drew on the depreciation of the Ghana currency, the cedi.

From these themes each group would create four garments from clothes and accessories sourced in the main market in Accra. The market provides many different types of clothing and footwear, as well as other products such as electrical goods, in relatively well-defined zones 
(see illustration 1) ranging from tweed hats to bedsheets. These products provided an almost open-ended resource on which the research was designed. The groups presented their proposals and storyboards and briefly explained their plans. Each group was allocated a 30 cedi (£6.00) budget to buy clothes and accessories from the Kantamanto market. This sum was agreed upon with the faculty staff as an appropriate amount to buy enough materials to allow for experimentation in the design process but still create new outfits. One of the authors independently assessed the market itself through informal discussions with traders and observations and these were recorded in field notes and photographs. Overall, the project ran for five days and culminated in presentations of finished garments modelled by the students.

Initially the student groups were briefed on the concept of upcycling and the parameters of the project: that any number of clothing items, including accessories could be bought within the budget. Bedsheets were allowed, although clothing was preferred in order to assess the possibilities of re-creating garments from other garments. The clothes could be cut up in any way and could also be hand-dyed using five coloured dyes, waxed to maintain the original colour of the fabric or with a small number of denim items, bleached. The choice and colour option of dyes, bleach and wax was determined by the resources available in the university fashion department. The aim of using these techniques was first, their familiarity to students and second to extend the opportunity to experiment with the creative process. While bleach is problematic in sustainability projects, in the mind of a typical Ghanaian it is a familiar product, associated with making things cleaner and consequently, re-usable. In this respect, the development of creative skills and student engagement were of primary importance; once these were understood in this project, learning about sustainability could be broadened in future projects to include the toxicity of bleaching and dyeing techniques. 
The groups took between one to two hours to select the materials, and then were allowed to return for more materials. They were given three days to design and cut and re-create clothes and accessories. The finalised designs were presented on day five, with short assessments of each project. A representative of each group was interviewed at the end of day two and from three groups on day three, as one group was involved in detailed sewing and the final group had returned to the market for more materials. Following their final presentations, students attended a short workshop to discuss the design process and outcomes of the project. Three design staff who had facilitated the project were interviewed as informed observers, for their insights into the process of creating upcycled clothing.

\section{Findings}

\section{The market}

The market in Accra extends over a number of small streets and alleys, around $600 \mathrm{~m}^{2}$ near the city centre (illustration 1). It sells clothes, shoes and accessories but also a wide range of electrical goods, food, plumbing and hardware, paint and decorating materials. Clothing forms a very large part and is organised by gender, womenswear, menswear, children's and by category including shirts, skirts, undergarments, denim, bedding, bedsheets, towels, so that different areas in the market specialise in types of clothing. The garments are further defined by their quality in three grades: $1^{\text {st }}$ grade, sales and rejects, unused: $2^{\text {nd }}$ grade slightly used: and $3^{\text {rd }}$ grade heavily used. 


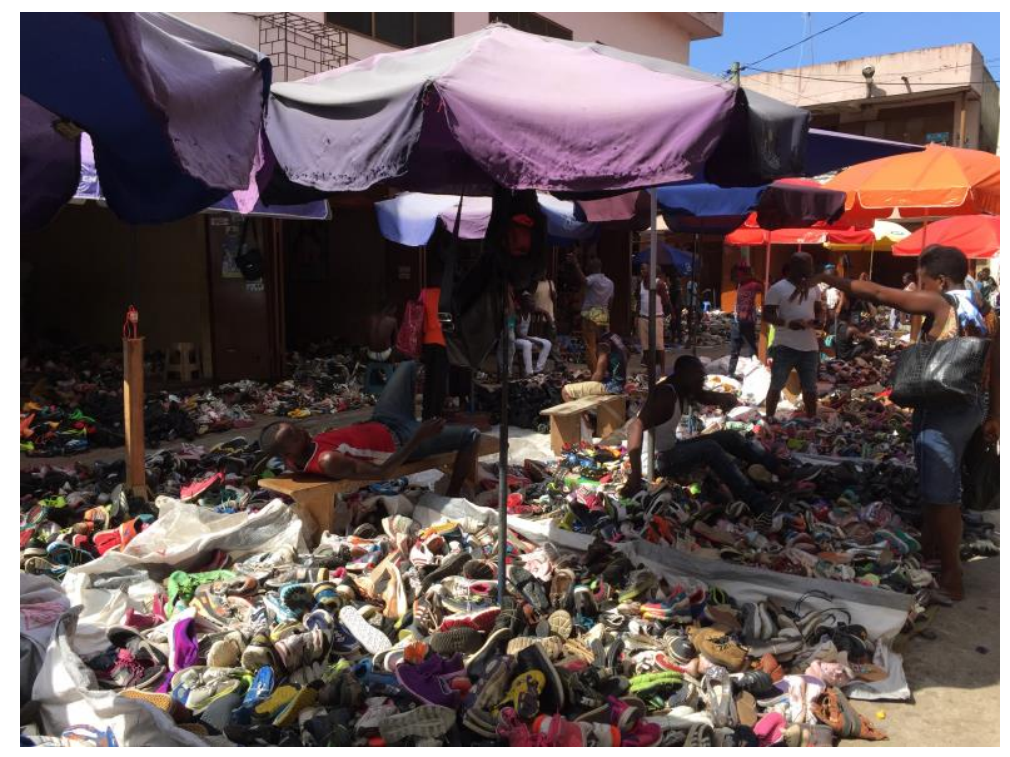

Illustration 1 Kantamanto market

Market trading is conducted from small open fronted units, stalls and the street itself. Amounts of goods stocked and sold by each trader can be assessed by the breadth, width and height of the displays, which are randomly laid out. Occasionally the trader will lay out and display individual garments or small collections, but the vast majority are displayed in unsorted piles. Nevertheless there is a distinct distribution chain from importers, through freight forwarders who organise customs clearance and the delivery of containers of clothing to the goods' owners in the market. The merchandise is delivered in containers from China and Europe, primarily the UK (Brooks, 2015). The distributors or informal wholesalers are able to access the packing lists of each shipping container and can identify and make buying decisions based on its contents. These are delivered to clothing warehouses in the middle of the market - there is a separate enclave for electrical goods - and the buyers collect their orders known as 'the truck', from the warehouse and pay in cash or at the bank. A bale can cost around 2000 Ghanaian cedi (£400) depending on its size. Bales from China are bigger, with about 250 in each container, while from the UK there are about 300-320 bales per container. Around a hundred containers can be delivered in one week to the market and the delivery quantities increase during seasonal periods, for example at Christmas. 
The project was explained to four traders at the market and their comments were summarised after the visit. The main finding was the traders thought the project was surprising, since they saw the market as a dumping site. One market stallholder was sceptical that any upcycled merchandise would sell, since it would be too expensive. Moreover, there were perceived limits on what could be used: heavily used garments were not seen as upcyclable. One trader, a jeans repairer was also sceptical and queried where the value lay: if people had disposed of the garments in the first place, were they likely to buy them back again. The respondents questioned what could be done to add value to a garment and expressed concerns about who would buy. It was observed that some recycling was undertaken in the market. There were at least two alleyways in which repairers congregated to repair and hand dye heavily used or torn garments or to alter them for re-sale. One example of this practice was cutting down the legs of knee length surf shorts and making two shorter shorts out of one garment.

\section{Market purchases and design inspiration}

Thematic analysis of the observations and interviews with participants, demonstrated the key activities in upcycling design, which were the investigation of possibilities, the creative processes in designing for re-use, prototyping and dyeing. The first of these activities commenced before visiting the market; the themes, storyboards and plans for outfits were used as a guide to what to look for and acquire. However, the themes themselves could present initial problems of interpretation and realisation. The 'architecture and monarchs' group drew on classical building cupolas and asymmetrical, postmodern roof shapes for their design researched from the Internet. The aim here was to bring different shapes together to create unisex designs, which - before visiting the market - required some detailed thinking about 
exactly what garments or materials could respond to this challenge. Acquisition of materials for the 'gathering and hunting' theme was more straightforward as this project planned to seek fake fur to create a primitive look. The nature theme based on forests and leaf patterns was less restrictive but was ultimately reduced to materials and new designs referencing 'nature'.

Four groups planned to buy ready-made clothes and to adapt them; in some cases specific garments were sought, for example unlined cotton garments to realise the nature design theme. In general larger shirts, tops and skirts allowed for more scope to create the main parts of the new outfit. By contrast the nature group deliberately chose a more radical route by buying a mix of readymade garments but also accessories to take apart or combine with other items. However, sourcing materials in the market presents specific difficulties, as there are many choices to be made from shapes and fabrics rather than conventionally designing with new materials from a small range of fabric choices. The market itself provided further inspiration and ideas to the designers, by opening up possibilities from browsing the stalls and displays. Some acquisitions were based on the attractiveness of individual garments and accessories as well as their potential for conversion into a new product. The fabric itself could determine the garment choice, requiring conscious decisions about "what do we need from the fabric" to achieve the design and how the garment lent itself to a design. Plans could change, as the impulsive appeal of denim overtook the idea of dancewear in one case, and items were described as 'very attractive' or 'so lovely'.

The market, therefore had an agency in defining the garment selection process, from the types of garment available and the influence of individual products on the designers. This was reflected in the time spent making purchases at the market. Around one-two hours were 
required to select and buy products with one group illustrating the problem of visualising a collection from waste garments, having to return to it on day three to make additional purchases:

"Some of the difficulties we had when we were going to the market, was what to choose, the main thing to choose, and how are we going to combine them together in the outcome? How is the outcome going to be?"

The number of items bought at the market varied between four and fifteen pieces and included shirts, skirts, a coat, jackets, bedsheets, belts, and bags. There was no distinctive approach to size or colour, although two groups, 'Everyone needs someone' and 'Degraded economy' bought denim, some of which was bleached white. Given the budget, which each group used up, the cost of each purchase ranged from 2 cedis $(£ 0.40)$ to 7.5 cedis (£1.40) from which two - three garments and additional accessories were created. Given the many different types of garment bought and their very different uses, it is difficult to estimate the material cost of an upcycled new garment. However, assuming three old garments were used to create each new one, the cost would be around $£ 1.80$ each. The five dyes bought for and used up in the project, cost 35 cedis in total (£7) although it was difficult to allocate the dye cost to each garment due their size and make-up. Moreover, three - four accessories, typically necklaces, were deconstructed directly from bags from which the groups also made belts, hair bands, a shoe and a fascinator. This intense use of the purchased items spread over a wider range of new outfits, would lower the material cost per garment.

\section{Product development}


The number of new garments under development tended to decline as decisions about the designs became more complex and new opportunities emerged. Groups went about product development using three different approaches: first, by cutting up original garments, shirts, jackets and skirts, and joining parts together to create a new garment, for example a shirt becoming an off the shoulder blouse or a dress. Second, by cutting up garments and using them to add details to an emerging new garment. In this way the 'Everyone needs someone' group began to adapt a denim jacket by using denim jeans pocket details from another garment for the back of the garment.

A third method was to use the original materials in a completely new way. A particularly successful example was the creation of a skirt from fabric belts, dyed in two colours and sewn together:

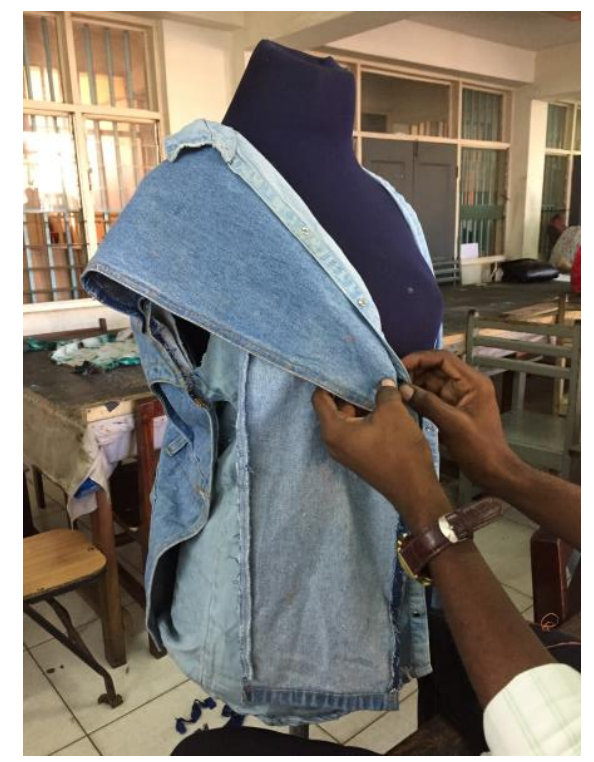

Illustration 2: Restyling a denim jacket 
Less adventurously but as effective, were shorts made from a shirt:

"These are the shorts. It (sic) was constructed from an off shoulder long sleeved shirt. A batik effect, we waxed it to block some of the whites in it".

The experience of creating new garments from old ones was explained as "interesting" "how we are dying things and combining colours to get a certain colour" but also "amazing" and "wonderful" in the context of stimulating new ideas and learning to use design skills in new ways. The observational analysis demonstrated the young designers' sense of working with materials to explore opportunities and that in a low technology environment, there was a sense of materiality through handling waste clothing and accessories to organise and understand it as an initial exploration. The observations further demonstrated the range of creative new designs. Some designers very carefully considered the implications of their theme; in developing the 'Neolithic theme' one student observed that people must have 'used bones and the like' and most work was done by hand. So in undertaking their re-construction, the students also used hand stitching, to try to achieve the same effect. On the other hand, the 'Degraded economy' group fell behind trying to interpret their storyboard and subsequently demonstrated less engagement with the project and less creativity, as evidenced in the conceptualisation and execution of their designs.

All groups dyed or bleached at least one garment and achieving the right final colour was a learning process in itself. Different fabrics and thicknesses were understood to affect absorption rates resulting in uneven colours and unexpected, and undesired colours. Experimentation in achieving the required dyed effect was recognised as a key part of this 
process. The dyed garments were typically given a pattern or effect by batik or tie-dyeing them and the analysis demonstrated two aspects of the dyeing process. First, it tended to contribute to the more original and successful designs but it also held up the making of the garments and clearly limited some of the outputs. The delays with dyeing provided other opportunities to effectively time-manage the project by considering and developing other ideas while the dyed materials were drying. To solve making-up problems with the unusual mix of materials required a degree of experimentation. The belts bought to make a skirt proved too thick for the sewing machine and broke all its needles. They had to be laboriously hand stitched together by one of the male students.

The development of accessories was undertaken in parallel with the garments as the original items were disassembled. Bags made from natural woven materials and with different types of handles could be broken down into necklaces and footwear. Wooden handles were glued together and threaded onto cord and fibre handles were re-plaited or twined to achieve a variety of necklace designs in keeping with each group's design theme. Material from woven bags was used by one group to create a sample of an ankle boot (which was modelled) and a necklace, although shortage of time prevented this from being realised in more detail:

"We are thinking of making a gladiator shoe or gladiator sandals with the body of a bag, a basket weave bag, we are also going to use ... (the) bag handles for a choker necklace .."

One theme that emerged was to describe the upcycling process in two stages, conversion and transformation of the purchased products. The designers ceased seeing the original garments as 'shirts' but as spaces or materials in the process of becoming new things. This stage of the 
project required creative problem-solving in order to envision garment parts in new forms. As the project moved on, there was for some, a sense of seeing new opportunities to use not only a few parts, but all the parts of the original products that resulted in an improved utilisation overall.

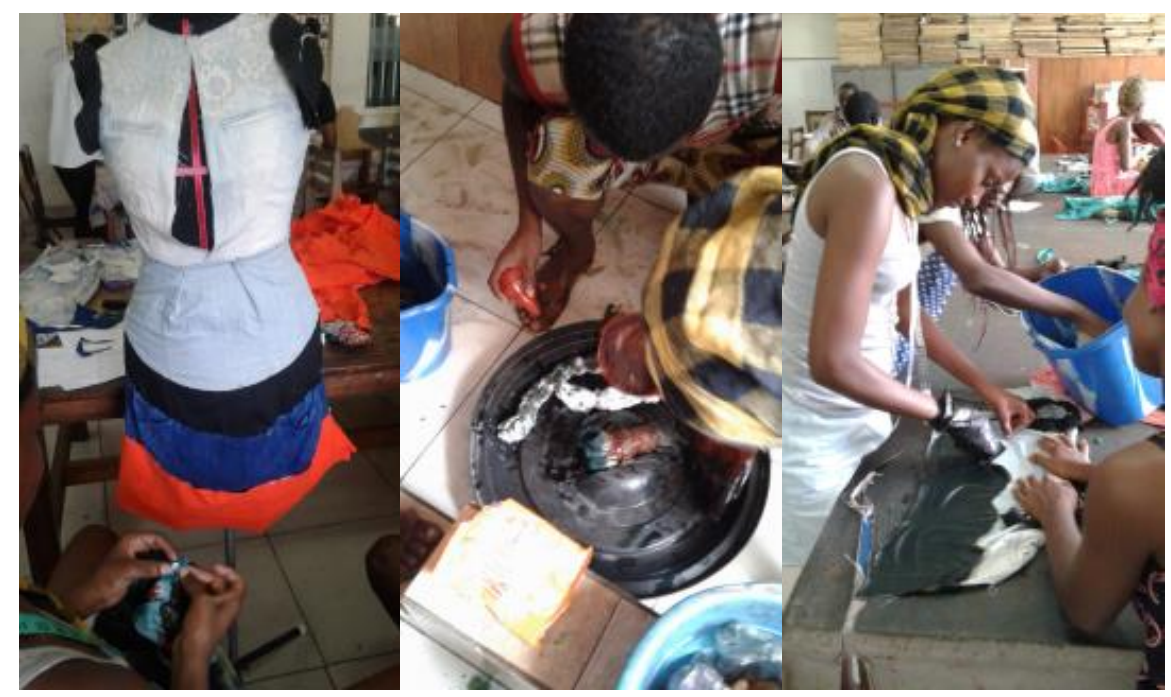

Illustration 3: Hand dyeing

\section{Design finalisation}

The presentation of the new garments demonstrated how the groups had used different design approaches. Each completed two to four garments with relatively little difference in quality.

Development time spent on the conceptualisation and adaptation of the bought garments 


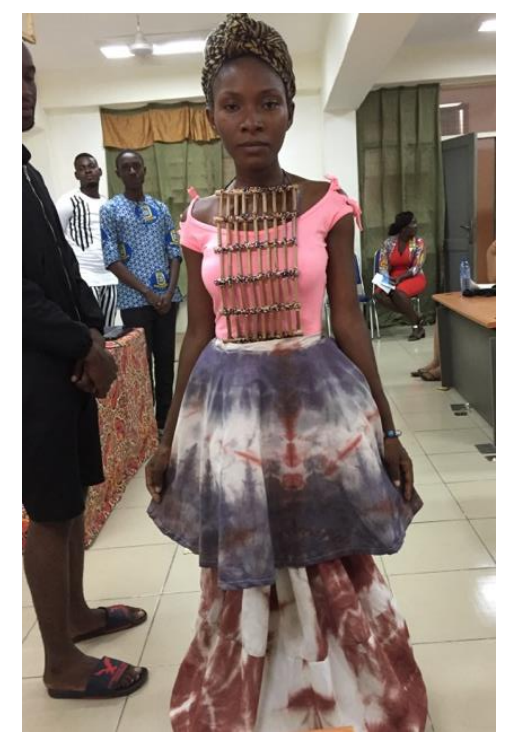

Illustration 4: Design finalisation

generally resulted in more original designs. The final collections and their potential use were well thought through in a Ghanaian context, for example for beach and street dance.

Given the problems of re-imagining and escaping the identities and physical characteristics of the bought garments, as 'shirts' for example, their shapes and constructions, the coherence of the new designs was notable. In most cases the groups achieved distinctively different garments. The group using the architectural theme interpreted cupolas, notably Brighton Pavilion and (unacknowledged) asymmetrical buildings from their visual story board into outputs that included a necklace made from sticks with beads, and a dyed bedsheet adapted into two layers of a skirt (Illustration 4). Bed sheets may have offered the most straightforward 'blank canvases' but shirts, jackets and trousers, were successfully used. From a photographic analysis of the finished outfits, most other non-clothing items, notably bags were imaginatively taken apart and used as extensively as possible for necklaces, headbands and shoes. A problem in following an abstract brief resulted in fewer creative outputs for the 'Degraded economy' 
group although they created one complete ensemble with a commercial, if not particularly original application.

In interviews, the group members reflected on their achievements in the project. The 'nature' group highlighted the re-iterations required in dyeing fabrics like denim to achieve the correct colour: one challenge in the project was to deal with issues of material consistency and absorbency. A second theme, was that the process of sourcing in the market would have been an easier if members had sought advice from each other and worked to plan, although some of the more successful designs were from unplanned purchases. The project was explained too as developing skills and knowledge, with one group reflecting on their outputs and commenting that they would have started with more dyeing. Generally the dyed products demonstrated successful design solutions, even if the dyes were not always successfully matched for shade.

Further analysis of the interviews with non-participant staff members highlighted some technical limitations during the project, in particular weaknesses in dyeing skills and the knowledge to achieve desired colours and appearances. More positively, the staff highlighted the creativity of the groups and described the beauty of the new garments, in much the same way as the students had: it was perceived that they had uncovered a new aesthetic from the everyday clothes in the market. In part this was achieved by the students' ability to innovate during the workshop by using their hand skills to re-interpret the clothes as materials for new items, not necessarily clothes but accessories or shoes. There were unusual limitations to overcome, in the deconstruction of existing forms and the need to adapt from the conventional possibilities of "neat, plain fabric", its tidiness and predictability, to the bricolage of cutting up, taking apart, dyeing and bleaching. The project was seen as an exploration, a way of breaking 
out of conventional design thinking to transform individual garments. The distinctiveness of the new garments was conceptualised by one respondent as the creation of stage or carnival costumes that would satisfy consumer demands for distinctive dressing.

The staff agreed that the project had potential for further development. Beforehand, it was anticipated that there might be a problem with finding a reliable source of similar clothes in the market to consistently meet the specifications of a garment order. However, this was not the case; the market had plenty of each type of garment and material, for examples bedsheets and denim to enable designs to be realised for at least small commercial orders. There was simply so much 'stuff' coming in each week that disposing of surplus merchandise from the market was seen as more of a problem. To use these waste materials would require a programme to ensure their durability, their propensity to take up dye, and colour fastness. Two further unstated considerations would be to devise and implement a process to sterilise any purchases from the market and from a commercial perspective, to adopt a new approach to planning and negotiating from this unconventional source.

\section{Conclusion}

The project aimed to explore the opportunities for designing new garments from waste clothing in the Accra market, the destination of a large number of second hand and reject clothing from Europe, China and Korea. It addressed the disposal stage of the circular economy model, applied to clothing sustainability by providing new knowledge of how waste clothing, readily available in a developing country's market can be sourced and creatively re-imagined into new garments and accessories. The findings support studies into the literature of the circular 
economy by focusing on a sector - the fashion clothing industry- and its products and materials and the significance of the recycling and recovery stage (Kalmykova et al. 2018; Kirchherr, et al. 2017; Prieto-Sandoval, Jaca and Ormazabal, 2018). By focusing on the Accra market, this study has provided further insights into the role of the market for the distribution of clothing and textiles and as a source of waste clothing and accessories for re-design and upcycling.

However, the research extends knowledge of value creation practices identified in earlier studies which have focused on repair and development of waste clothing by market-based workers and the creation of new collections by trained designers inspired by and using local textiles. This project demonstrates the potential for a design-led approach to upcycling waste clothing in sourcing waste clothing and textiles in the market and the creativity required to reconceptualise into new products. In the workshop, the stages of the design process began with the relatively conventional development of themes which were informed by research primarily from the Internet, visualised in a storyboard with samples of textiles and other materials and explained in a brief statement. The second stage saw the start of a more emergent approach, as clothing and accessories were acquired from the market and included the sourcing of interesting and appropriate products to a pre-formed plan but also being inspired by products in the market. This stage demonstrated the importance of the market as a physical resource with predictable product categories but unpredictable individual products, which could stimulate new ideas and design concepts. These elements provide a creative opportunity for upcycling that extended beyond the existing local market economy and employment.

The third stage was an investigation of design possibilities, as individual products were assessed for their potential and which led to their deconstruction and/or dyeing and the stitching 
and sewing of new garments. This was followed by the development of the finished garment and its realisation as a higher value item. The value of the item was defined by its re-use as a more desirable object, for example necklaces created from bag handles and skirts from belts, in the creation of new garments from low value products - dresses from bed sheets - and unique designs arising from re-conceptualising and re-modelling waste tops and bottoms. Following DeLong et al. (2017) it was clear that the design process required a greater focus on the material than in conventional design projects. Finally the teams presented two-four finished outfits as evidence of their creativity and experimentation which they modelled in fashion shows.

In this study two significant influencing conditions for upcycling were identified: accessibility conditions, requiring access to a wide range of products in the nearby market at affordable prices, and facilitating conditions which enable designers to store, assess deconstruct and develop new products. The project did not aim to produce commercial collections, so only a limited number of garments had an immediately evident commercial potential. Nevertheless, the collections in the 'Everyone needs someone' and 'Nature' groups demonstrated creative solutions to using denim in the first of these groups and to using a diverse range of "nongarments', belts, bags and sheets, in the second.

Further research will extend the findings from the project. Taking the Design Council's 'Design Diamond' model (Design Council, 2019) the discovery stage presented unusual contextual problems: the Accra market is defined by space and conventions of ownership and uses. However, within this relatively stable framework, in keeping with all markets there is an instability of availability, an uncertainty of what is available and where. In the second stage of the diamond model, defining the problem, there is a need to find methods to escape from the 
constraints of the visual language of existing garments and their labels. At this point and in this context, there is a need to create a language of re-design and upcycling for second-life clothes and accessories. The development and delivery stages of design for commercially viable solutions are much further away. This initial project suggests that future research could be undertaken to explore the significant local learning requirements for branding, marketing, particularly international market entry strategies and the feasibility of SME business organisation(s) to achieve a successful business model.

\section{References}

Abimbola, O. (2012) The international trade in second-hand clothing: managing information asymmetry between West African and British traders. Textile: The Journal of Cloth and Culture, Vol. 10, No.2, pp. 184-199.

Adikorley, R. D. (2013) The Textile Industry in Ghana: A Look into Tertiary Textile Education and its Relevance to the Industry. Unpublished MSc. Thesis. Available at: https://www.researchgate.net/publication/274070597 [Accessed 3/7/19].

Aditomo, A. Goodyear, P. Bliuc, A. and Ellis, R.A. (2013) Inquiry-based learning in higher education: principal forms, educational objectives and disciplinary variations. Studies in Higher Education, Vol. 38, No. 9, pp. 1239-1258. 
Baden, S. and Barber, C. (2005) The Impact of the Second-Hand Clothing Trade on Developing Countries. Oxfam International: Oxford.

Balch, O. (2013) H\&M: Can fast fashion and sustainability ever really mix? The Guardian [online]. Available at: https://www.theguardian.com/sustainable-business/h-and-m-fashionsustainability-mix [Accessed 20/05/15].

Bartlett, C. McGill, I. and Willis, P. (2013) Textiles Flow and Market Development Opportunities in the UK. WRAP: Oxford.

Bramston, D. and Maycroft, N. (2013) Designing with waste. In E. Karana, V. Rognoli, and O. Pedgley (Eds.) Materials Experience: Fundamentals of Materials and Design. Butterworth-Heinemann: Oxford, pp. 123-133.

Braungart, M. McDonough, W. and Bollinger, A. (2007) Cradle-to-cradle design: creating healthy emissions - a strategy for eco-effective product and system design. Journal of Cleaner Production,Vol.15, Nos. 13-14, pp.1337-1348.

Brooks, A. (2012) Riches from rags or persistent poverty? The working lives of secondhand clothing vendors in Maputo, Mozambique. Textile, Vol.10, No.2, pp.222-237. 
Brooks, A. (2015) Clothing Poverty: The Hidden World of Fast Fashion and Second-Hand Clothes. Zed Books: London.

Claxton, S. and Kent A.M. (2017) Design management of sustainable fashion. In the Proceedings of the EURAM Conference. Strathclyde University, June 22-24th.

Cooper, T. Claxton, S. Hill, H. Holbrook, K. Hughes, M. Knox, A. and Oxborrow, L. (2013) Development of an Industry Protocol on Clothing Longevity. Report produced for Waste and Resources Action Programme (WRAP). Nottingham: Trent University Nottingham.

Delong, M. Casto, M.A. Min, S. and Goncu-Berk, G. (2017) Exploring an up-cycling design process for apparel design education. Fashion Practice, Vol. 9, No. 1, pp. 48-68.

Design Council (2019) What is the Design Process: Introducing the Double Diamond? Available at https://www.designcouncil.org.uk/news-opinion/design-process-what-doublediamond. [Accessed 2/2/19]

Ellen MacArthur Foundation (2015) Towards a circular economy: Business rationale for an accelerated transition. Ellen MacArthur Foundation. Available at: https://www.ellenmacarthurfoundation.org/assets/downloads/TCE_Ellen-MacArthurFoundation_9-Dec-2015.pdf. [Accessed 11/09/18]. 
Fletcher, K. (2008) Sustainable Fashion and Textiles: Design Journeys. Earthscan:London.

Fletcher, K. and Grose, L. (2012) Fashion and Sustainability: Design for Change. Laurence King: London.

Fraser, K. (2011) Case study: Upcycling materials for fashion. In: A. Gwilt and T. Rissanen (Eds) Shaping Sustainable Fashion: Changing the Way We Make and Use Clothes. Routledge: London, pp. 35-38.

Frazer, G. (2008) Used Clothing Donations and Apparel Production in Africa. The Economic Journal, Vol.118, No.532, pp.1764-1784.

Gardetti , M.A. and Torres, A.L. (2013) Sustainability in Fashion and Textiles. Greenleaf: Sheffield.

Goldsworthy, K. (2009) Resurfaced: Using laser technology to create innovative surface finishes for recyclable, synthetic textiles. Cutting Edge: Lasers and Creativity Symposium, Loughborough University. Online. Available from http://www.cuttingedgesymposium.com/pdf/kate-goldsworthy-paper.pdf [Accessed 4/7/18]

Gwilt, A. (2014) A Practical Guide to Sustainable Fashion. AVA Publishing: London. 
Gwilt, A. and Rissanen, T. (2010) Shaping Sustainable Fashion: Changing the Way we Make and Use Clothes. Earthscan: London.

Haggblade, S. (1990) The flip side of fashion: Used clothing exports to the third world. Journal of Development Studies. Vol. 26, No.3, pp.505-5210.

Han, S.L.C. Chan, P.Y.L. Venkatraman, P. Apeagyei, P. Cassidy, T. and Tyler, D. J. (2017) Standard vs. upcycled fashion design and production. Fashion Practice. Vol.9, No. 1, pp. 6994.

Hansen, K.T. (2000) Salaula: The World of Secondhand Clothing and Zambia. The University of Chicago Press: Chicago.

Hill H. Taylor, R. and St.John-James, A. (2015). Global perspectives and translations of consuming waste in the present. In the Proceedings of the Product Lifetimes and the Environment (PLATE) Conference, Nottingham Trent University: Nottingham

Hurney, C. A. Nash, C. Hartman, C.-J. B. and Brantmeier, E. J. (2017) Incorporating sustainability content and pedagogy through faculty development. International Journal of Sustainability in Higher Education, Vol.17, No.5, pp.582-600. 
Joergens, C. (2006). Ethical fashion: myth or future trend? Journal of Fashion Marketing and Management: An International Journal, Vol.10, No.3, pp. 360-371.

Kalmykova, Y. Sadagopan, M. and Rosado, L. (2018) Circular economy - From review of theories and practices to development of implementation tools. Resources, Conservation and Recycling, Vol.135, pp. 190-201.

Kirchherr, J. Reike, D. and Hekkert, M. (2017) Conceptualizing the circular economy: An analysis of 114 definitions. Resources, Conservation and Recycling, Vol.127, pp. 221-232.

Langevang, T. and Gough, K.V. (2012) Diverging pathways: young female employment and entrepreneurship in Sub-Saharan Africa. The Geographical Journal, Vol. 178, No. 3, pp. $242-252$.

Lee, Y. K. and Delong, M. (2018) Rebirth product development for sustainable apparel design practice in a design studio. Fashion Practice, Vol.10, No.1, pp.34-52.

Liedtke, C. Buhl, J. and Ameli, N. (2013) Designing value through less by integratin sustainability strategies into lifestyles. International Journal of Sustainable Design, Vol. 2, No. 2, pp. 167-180. 
Manteaw, O.O. (2012) Education for sustainable development in Africa: the search for pedagogical logic. International Journal of Educational Development, Vol. 32, No. 3, pp. 376-383.

Manzini, E. (2015), Design, When Everybody Designs - An Introduction to Design for Social Innovation.The MIT Press: Cambridge MA.

McDonough, W. and Braungart, M. (2009) Cradle to Cradle: Remaking the Way We Make Things. Vintage.:London.

McGrath, H. and O'Toole, T. (2012) Critical issues in research design in Action Research in an SME Development context. European Journal of Training and Development, Vol.36, No.5, p.508-526.

Oteng-Ababioa, M. Sarfob, K.O. and Owusu-Sekyere, E. (2015) Exploring the realities of resilience: Case study of Kantamanto market fire in Accra Ghana. International Journal of Disaster Risk Reduction, Vol. 12, pp. 311-318.

Oxfam (n/d) Inside Frip Ethique. Oxfam Report. Available at https://www.oxfam.org.uk/donate/donate-goods/what-happens-to-your-donation/inside-fripethique. [Accessed 20th March 2018]. 
Parsons, G. (2016) Philosophy of Design. Polity Press: Cambridge.

Piller, F. Schebert, P. Koch, M. and Moslein, K. (2005), Overcoming mass confusion: collaborative customer co-design in online communities. Journal of Computer-Mediated Communication, Vol.10, No.4. Online. Available at:

http://jcmc.indiana.edu/vol10/issue4/piller.html [Accessed 24/9/2017].

Pretorius, R. Lombard, A. and Khotoo, A. (2016) Adding value to education for sustainability in Africa with inquiry-based approaches in open and distance learning. International Journal of Sustainability in Higher Education, Vol. 17, No.2, pp.167-187.

Prieto-Sandoval, V, Jaca, C. and Ormazabal, M. (2018) Towards a consensus on the circular economy, Journal of Cleaner Production, Vol. 179, pp. 605-15.

Reason, P. (1994). Three approaches to participative inquiry. In: N. K. Denzin and Y. S. Lincoln (Eds.), Handbook of Qualitative Research, pp. 324-339. Sage: London.

Sanders, E. B.-N. and Stappers, P. J. (2012) Convivial Toolbox: Generative Research for the Front End of Design, BIS Publishers: Amsterdam. 
Shaw, J. (2013) Fashion Made in Malawi - MIA by Mia Nisbet SS14 collection. Africa Fashion Guide. Available from https://www.africafashionguide.com/fashion-made-inmalawi-mia-by-mia-nisbet-ss14-collection-designer/ Accessed 21/3/19.

Weber, S. Lynes, J. and Young, S.B. (2017) Fashion interest as a driver for consumer textile waste management: Reuse, recycle or disposal. International Journal of Consumer Studies, Vol.41, No. 2, pp. 207-215.

WRAP (2015) WRAP's response to the European Commission's Circular Economy package. [Online]. Available at: http://www.wrap.org.uk/blog/2015/12/wrap\%E2\%80\%99sresponseeuropean- commission\%E2\%80\%99s-circular-economy-package. [Accessed 12/09/16]. 